\title{
Mancha Foliar de Pseudocercospora ocimicola em Ocimum selloi
}

\author{
João de Cássia B. Costa ${ }^{1}$, José L. Bezerra ${ }^{1}$, Larissa C.B. Costa ${ }^{2}$, Eduardo Alves ${ }^{3}$, Anderson R. Almeida ${ }^{3}$, \\ Eloísa A.G.L. Lopes ${ }^{3}$, José E.B.P. Pinto ${ }^{4}$
}

${ }^{1}$ CEPEC/CEPLAC/MAPA, Cx. Postal 07, CEP 45650-000, Itabuna, BA, e-mail: jcbioctrl@ceplac.gov.br; ${ }^{2}$ Departamento de Ciências Biológicas, Universidadade Estadual de Santa Cruz, Rod. Ilhéus-Itabuna, km 16, CEP 45650-000, Ilhéus, BA;

${ }^{3}$ Departamento de Fitopatologia; ${ }^{4}$ Departamento de Agricultura, Universidade Federal de Lavras, Cx. Postal 3037, CEP 37200-000, Lavras, MG

(Aceito para publicação em 03/07/2006)

Autor para correspondência: João de Cássia do Bomfim Costa

\author{
ABSTRACT \\ Pseudocercospora ocimicola leaf spot on Ocimum selloi \\ Ocimum selloi is reported for the first time as a host of Pseudocercospora ocimicola.
}

Ocimum selloi Benth. é uma espécie medicinal da família Lamiaceae conhecida popularmente como alfavaquinha, atroveran ou elixir-paregórico. $\mathrm{Na}$ medicina caseira, é empregada para o controle de gases intestinais, gastrites, vômitos, tosses, bronquites, gripes, febres e resfriados (Lorenzi \& Matos, Plantas medicinais no Brasil: nativas e exóticas cultivadas 2002). Resultados preliminares confirmaram a sua atividade antiespasmódica, analgésica, antiinflamatória (Vanderlinde et al., Simpósio de Plantas Medicinais do Brasil, 13, 1994) e o seu efeito como repelente contra mosquitos (Paula et al., Journal of Ethnopharmacology 88: 253. 2003). Folhas amarelas com manchas foliares foram observadas em plantas de $O$. sello $i$ cultivadas no Horto de Plantas Medicinais da Universidade Federal de Lavras. Os sintomas caracterizaram-se pela presença de lesões foliares castanho-claras isoladas ou coalescentes, dispersas, subcirculares, de bordos irregulares com dimensões variando de 3 a $5 \mathrm{~mm}$ de diâmetro ocorrendo, principalmente, em folhas maduras situadas até o terço inferior da planta (Figura 1A). Quanto às características morfológicas do fungo, observaramse estromas intraestomáticos (Figura 1E), castanhos, cilindráceos, pseudo-parenquimáticos, irrompentes, 14$24 \mu \mathrm{m}$ de diâmetro. Micélio interno escasso formado de hifas inter e intracelulares. Conídios filiformes, hialinos, 5-9 septados, 97-310 × 2-3 $\mu \mathrm{m}$ (Figuras 1B, C e D). Conidióforos subhialinos, septados, geniculados, simples ou ramificados na base, $58-178 \mu \mathrm{m}$ de comprimento e 2,5-5 $\mu \mathrm{m}$ de diâmetro na parte mediana (Figuras 1B -E). Estas características conferem com a descrição da espécie $P$. ocimicola (Petr. \& Cif.) Deighton que já foi descrita sobre Ocimum sp. (Brasil), Marsypianthes chamaedrys (Vahl) Kuntze (Brasil), O. americanum L. (Myanmar), O. basilicum L. (China, Taiwan), $O$. gratissimum L. (Cuba), O. sanctum L. (Cuba, Myanmar) (Braun \& Freire, Cryptogamie Mycologie, 23:295. 2002), O. kilimandscharicum Gürke e O. micranthum Willd. em outros países como República Dominicana, Fiji, Índia, Nova Zelândia, Taiwan e Vanuatu (Crous \& Braun, Mycosphaerella and its anamorphs: 1. Names published in Cercospora and Passalora. 2003). O comprimento dos conídios em $O$. selloi excede aquele apresentado por F.C. Deighton (Mycological Papers 140:1-168. 1976). Este é o primeiro relato de $P$. ocimicola em $O$. selloi.
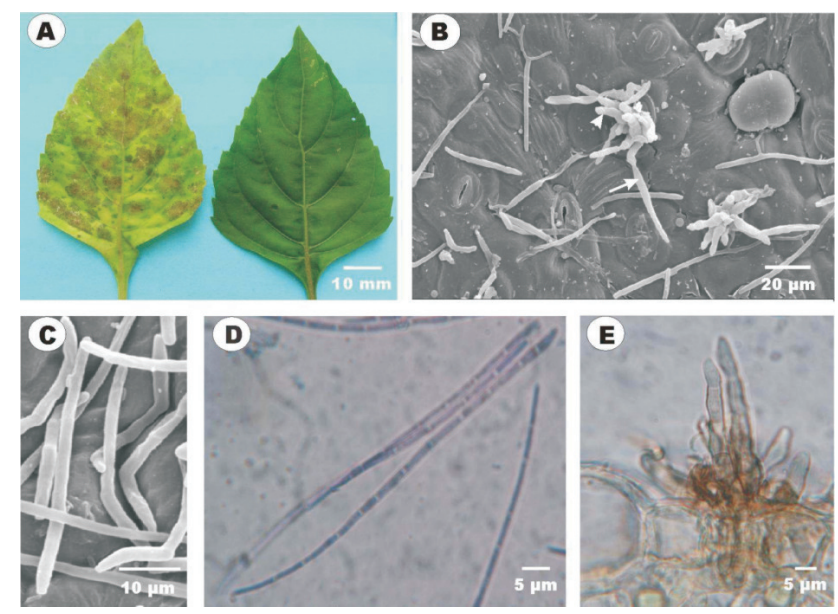

FIG. 1 - A. Folha de Ocimum selloi com sintomas de Pseudocercospora ocimicola à esquerda e sem sintomas à direita; eletromicrografias de varredura: B. superfície foliar evidenciando célula conidiogênica (cabeça de seta) e conídios (seta); C. conídios; fotomicrografias: D. conídios e E. conidióforos. 